\title{
Interlingual Malapropism in a Bilingual Context: Insights from Icheoku and Masquerade
}

\author{
Diri I. Teilanyo \\ University of Benin, Benin City, Nigeria
}

\begin{abstract}
This paper investigates the linguistic defect of malapropism in two Nigerian media comedies, Icheoku and Masquerade. Using mainly qualitative content/textual analysis, the paper demonstrates that malapropism in a second-language bilingual context is a consequence not only of inadequate mastery of the vocabulary in a language (as in a monolingual's malapropism) but also of interference from the subordinate bilingual's first language or mother tongue with the target second language (and vice versa). In contrast with the classical pattern where lexical items in the same language are confused, in interlingual malapropism the confusion is between lexical items in two (and possibly more) languages which share some phonological affinity. The artistic element in this linguistic phenomenon as exemplified by the two series is also examined. Thus, it is demonstrated that malapropism is a (socio-)linguistic problem that is satirized in fictional terms in the two works. The findings here complement and expand the classical notion of malapropism by taking cognisance of the incompetent bilingual in a multilingual setting.
\end{abstract}

Keywords: malapropism, interlingual malapropism, perceptive malapropism, art, parody, Icheoku, Masquerade DOI: $10.7176 / J L L L / 65-04$

Publication date: February $29^{\text {th }} 2020$

\section{Introduction}

A little learning is a dangerous thing;

Drink deep, or taste not the Pierian Spring:

There shallow draughts intoxicate the brain,

And drinking largely sobers us again.

(Alexander Pope 1973, lines 195-199)

The traditional notion of "malapropism" (from the archetypal fictional character Mrs. Malaprop in R. B. Sheridan's The Rivals, 1775) has essentially been in expressive and intralingual terms. In order words, the idea of malapropism has been that it is the way in which words and expressions (with some phonological similarity but different semantic features) within a specific language are confused as they are spoken or written. This concept is obvious in different definitions and/or examples given of the term. We find this in the following:

(a) "ludicrous misapplication of language; an instance of this" (Oxford English Dictionary, 1989).

(b) "verbal blunder in which one word is replaced by another similar in sound but different in meaning" (The Online Encyclopaedia Britannica, 2007)

(c) "a humorous confusion of words that sound vaguely similar, as in "We have just ended our physical year" instead of "We have just ended our fiscal year" (American Heritage New Dictionary of Cultural Literacy (2005)

(d) "ludicrous misuse of a word, especially by confusion with one of similar sound... An example of such misuse." American Heritage Dictionary of the English Language.(2009)

(e) "a mistaken substitution of one word for another that sounds similar, generally with humorous effect, as in "arduous romance" for "ardent romance." Literary Dictionary (2007)

(f) "unintentional use of wrong word: the misuse of a word through confusion with another word that sounds similar, especially when the word is ridiculous." Encarta Dictionary Online (2007).

(g) "the usually unintentionally humorous misuse or distortion of a word or phrase; especially the use of a word sounding somewhat like the one intended but ludicrously wrong in the context" Marriam-Webster's Online Dictionary (2007).

In its specification of the credentials of a malapropism, the Wikipedia Online Dictionary mentions outright "the speaker's or writer's language." In other words, malapropism is traditionally to be associated with the encoding language skills (speaking and writing) rather than with the decoding skills (listening and reading) which would have been expressed by "the listener's or reader's language." Again, the confusion is within a single language, not between or among languages. This is the point of departure for this study. It argues that malapropism may also be a phenomenon in both perceptive and interlingual terms, that is, in how wrongly a bilingual hears, understands or interprets a word or an expression between or among different languages. For example, where one language user produces a word or phrase that is semantically and contextually appropriate; his interlocutor out of his limited proficiency in that language may "mishear" or misunderstand that word or expression as being another word in another language that sounds like it, but has a different and generally 
ridiculous meaning in the context of utterance. The malapropism or confusion of phonologically contiguous but semantically distinct codes, then, is not on the part of the speaker or writer (as in the traditional notion), but that of the listener or reader who has perceived it wrongly as being in a word or phrase in another language which the speaker never spoke in the first instance.

Specifically, in perceptive malapropism, the unfitness or unsuitability of a word or expression becomes manifest not by one's use of the wrong word or expression but by one's interpretation of such word either through a wrong translation into another language or through a wrong physical or verbal response. In other words, the malapropriation arises from one's wrong perception or reception of the word at issue, where one misunderstands the term to be another with which there is some phonological affinity (but little or no semantic sameness). Perceptive malapropism may also arise among native speakers of a language, but it is particularly prominent among subordinate bilinguals whose mastery of their second language is significantly limited.

The situation is more complex when this perceptive malapropism is interlingual: where the subordinate bilingual "mishears" a word or utterance in the second language to be a word or utterance in the mother tongue (Igbo, in this case) as if the speaker (of English, in this case) had actually uttered the expression in the receiver's mother tongue.

The central proposition in this paper, then, is as follows: Icheoku and Masquerade are artistic demonstrations of the trend that in a second language context, malapropism is a consequence both of inadequate mastery of the lexico-semantic patterns of the second language and of interference from the indigenous mother tongue or first language.

\section{Method}

Icheoku and Masquerade are not in print (in their published forms). Icheoku is a television series produced by the Nigerian television Authority, NTA, most of the episodes by the Lagos national headquarters and a few by the Enugu national station. Therefore the texts are in the audio-visual medium (videocassettes). Masquerade is both a television and a radio series. Hence, it is in both the audio-visual and the audio media. The episodes in the audio medium - in long playing records and audiocassettes - have been chosen because this medium presents certain linguistic and paralingusitc features which are not manifest in the audio-visual (where the pictorial props reduces their prominence). The combination of the purely aural in Masquerade with the visual in Icheoku brings a fuller picture of the patterns and issues in second-language use. Relevant texts (of video episodes and audiocassettes) from each series have been faithfully transcribed for the analysis. For Icheoku the analysis in this paper is taken largely from the English sub-titles provided in the videotapes as much of the dialogue is in Igbo, one of the major languages in Nigeria whose environment constitutes the ethno-linguistic setting for the drama. Two bilingual dictionaries - Kay Williamson's Igbo-English Dictionary (1972) and H.I. Nnaji's Modern Igbo-English Dictionary (1985) have also aided the interpretations. An interview between Chief Chika Okpala, the man who has played the role of Chief Zebrudaya (Zebi) of Masquerade from the 1970's to date has helped in the interpretation of the sociolinguistic dimensions of the texts (Okpala, 1993). The researcher also resorted to Igbo native speakers as informants and resource persons as occasions demanded.

In subject matter, Icheoku and Masquerade are both comedies that satirize social issues. Icheoku deals with domestic and communal concerns in a typical traditional Igbo community during the colonial era. Each episode concentrates on some family squabble or social miscreant and the effort of the colonialists in the image of the District Officer (D.O) or District Commissioner (D.C) to dispense justice in a foreign terrain with the Court Clerk (C.C), who is severely handicapped in the D.O's language (English), as the interpreter from English to Igbo and vice-versa. ${ }^{1}$ Masquerade deals with contemporary issues in Nigeria with each episode focusing on a specific malaise in politics, religion, social manners, marriage, etc. But the comedies are given a highly linguistic tinge: the works equally ridicule linguistic manners, in that they parody the trials, travails and triumphs of the English language and its users in second-language settings. Icheoku aptly captures the intriguing challenges that attended the use of English as a vehicle for communication between the English monolingual colonial masters and the African monolingual populace through the instrumentality of interpreters like the Court Clerk. This suggests the name Icheoku, meaning "Parrot," which is the emblem used in the programme. This relates to Kachru's "regulative" function of non-native "Englishes" (Kachru 1983: 41-42). On the other hand, Masquerade is an eloquent demonstration of Kachru's "interpersonal" function of non-native Englishes where the language functions as a vehicle of communication among the members of Africa's multilingual nations and states. ${ }^{2}$

A word also needs to be said about the authorship of these texts. Although the scripts of the episodes are written by individuals, the authorship is normally ascribed to the body producing and presenting them since the text as performed normally involves much more than what is found on the script. Thus out of the many episodes of Icheoku studied, all those produced by the NTA Headquarters, Lagos, are written by Peter Eneh; two of the four produced by the NTA Enugu are written by Emeka Nwagwu while two have no script writer identified. Therefore, the authorship is ascribed to NTA Lagos and NTA Enugu respectively. Secondly, while all the episodes produced by the Lagos headquarters have titles, those produced by Enugu NTA have no titles. We cite 
the titles of those produced by NTA Lagos. For ease of reference to those by the NTA Enugu, the researcher suggests titles for them (enclosed in square brackets) based on the issues dealt with in them. For Masquerade all the texts are named. The LPs and audiocassettes are produced under two names to which the authorship is ascribed - James Iroha and the Masquerades, and Zebrudaya and His Concert Party.

On scholarship on such creative works adopting non-standard second language, Braj B. Kachru, while discussing the four functional aspects of non-native "Englishes", has lamented the lack of research into the "imaginative / innovative" function of "pidginized or "broken" variety" (Kachru, 1983, p. 41). He adds that "this [creative] aspect of non-native English has unfortunately not attracted much attention from linguists, but has now been taken seriously by literary scholars." Ayo Banjo has specifically called attention to the English spoken by Chief Zebrudaya, especially in terms of "aesthetic considerations" (Banjo, 1979, p. 11). David Jowitt has also made reference to the language of Chief Zebrudaya (Jowitt, 1991, p. 37) in his discussion of varieties of "Nigerian English," noting it as "severely sub-standard English" (p. 51). While the language used by these two speakers may appear idiolectal (even idiosyncratic - for Zebi), it must be emphasized that they are sociolinguistic "types"; hence "the variety of English which is being parodied does exist outside the NTV ${ }^{3}$ studios, and in many cases is the only variety its speakers are capable of" (Banjo, 1979, p. 11). However, lately the non-standard language used in Icheoku and Masquerade has received considerable academic attention (Teilanyo 2003a, 2003b, 2009, 2010).

The method of analysis adopted in this study is essentially textual content analysis without the invocation of any particular theoretical linguistic framework. In the analysis, however, specific principles and concepts are invoked from specific aspects of linguistics and literary criticism to explain the issues that arise.

\section{Result}

\subsection{A Typology of Malapropism}

Malapropism can be either intralingual or interlingual. It is intralingual when there is confusion of lexical items or expressions in a single language. On the other hand in interlingual malapropism an individual confuses lexical items in two different languages, lexical items that share some phonological feature(s). For a monolingual - like Mrs. Malaprop - only intralinqual malapropism is to be expected since the individual has no knowledge of any other language from which to transfer linguistic habits, but interlingual malapropism (along with the intralingual) would obtain for the subordinate bilingual who has inadequate mastery of one of the languages he uses. Both intralingual and interlingual malapropism may each be expressive or perceptive (or receptive). In expressive intralingual malapropism (which is the classical type), the malaprop speaks or writes one word that phonologically resembles but is semantically different from the appropriate one. The manifestation of this in The Rivals, Masquerade and Icheoku has been studied elsewhere (Teilanyo, 2011). In perceptive intralingual malapropism - which is studied elsewhere (Teilanyo, 2003a) - the malaprop in his response to a speaker's utterance demonstrates that he has misunderstood the word that was spoken as being another with which it has phonological affinity but no semantic affinity. Intralingual malapropism can be found in both monolingual and bilingual/multilingual contexts. Interlingual malapropism and its sub-types obtains only in bilingual/multilingual situations and is a manifestation of linguistic interference. In expressive interlinlingual malapropism, the malaprop utters a word in one language resembling a word in another language although there is no semantic relationship between them. In perceptive interlingual malapropism, the malaprop "mis-perceives" a word uttered in one language as being a word in another language in his linguistic repertoire.

These patterns are presented schematically as follows:

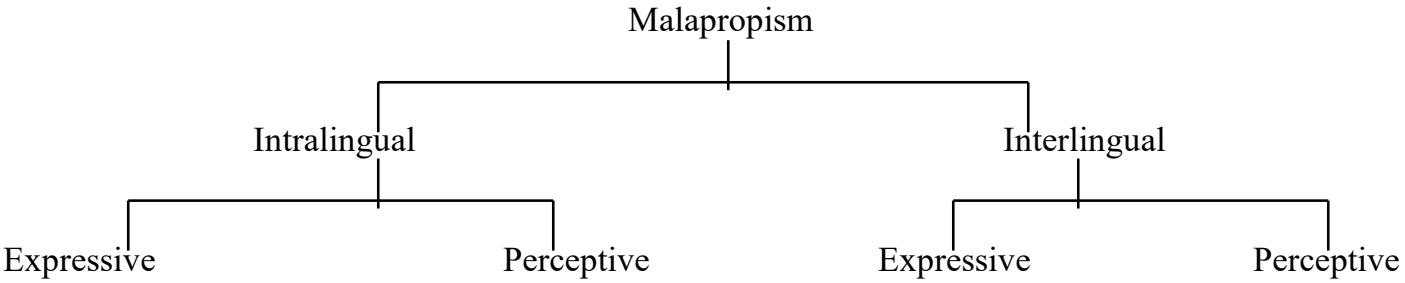

There is a large quantity of each of these types of malapropism in Icheoku and Masquerade -- expressive intraligual malapropism, perceptive intralingual malapropism and expressive interlingual malapropism and (perceptive) interlingual malapropism. ${ }^{4}$

The first two types and their reflection in the two mass media comedies have been discussed elsewhere (Teilanyo, 2003a): Only a few samples of each type are given below:

Expressive Intralingual Malapropism:

1. I would have her instructed in geometry, that she might know something about contagious countries,$- \ldots$ that she might reprehend the true meaning of what she is saying ... I don't think there is a superstitious article in it. [geography, contiguous, comprehend, superior] (Sheridan, 1966, p. 127). 
2. And we struggle all four corner of the world to confuse them to settle the matter with myself, not to go for court. $^{5}$ [convince] - NTA Icheoku "Inheritance"

3. After he have proscribe the medicine...[prescribed]. - Zebrudaya Masq. "Clarus the Psy."

4. MR. BANKROVITCH. If it is not here then why am I not in the right place.

OVULERIA. Eghen, rice plate? Hmm! Sorry-o, we no dey cook hotel here.

Perceptive Intralingual Malapropism:

$$
\text { - Iroha Masq. "Visit" }
$$

5. D.O. For instance, did you see the rainbow yesternight?

C.C. Yes, sir. I see it.

D.O. Very bold wonderful colours.

C.C. Ha-ha! (Interpreting in another language)[He said that yesterday bows and arrows were flying in the rain]

$$
\text { -- NTA Icheoku "Bush" }
$$

\subsection{Interlingual Malapropism in Icheoku}

In this section we wish to consider those malapropisms in which there is a false type of code-mixing ${ }^{6}$ involved in $^{-1}$ that the user, essentially the C.C in Icheoku, confuses English lexical items with Igbo lexical items - as if the D.O himself were using the Igbo lexical items. Such confusion of codes is generally perceptive or receptive in that the C.C does not, in these cases, do the mixing himself, but misperceives the D.O's (English) linguistic elements as Igbo elements.

The instances of interlinqual malapropism are of two main types - those involving Igbo proper names and those involving other Igbo lexical items.

\subsubsection{Igbo Proper Names}

6. D.O. Okay, Court Clerk, I'll like to hear from the Chief.

C.C. [Calling] Oke!

C.M. [Echoing] Oke!

OKE. Ogho!

C.C. [Who is Oke? Come out] (Oke advances.)

D.O. What's wrong? What's it?

C.C. I think you say you want Oke.

D.O. I said what?

C.C. Oke. -- NTA Icheoku "Bride"

7. D.O. Why is it that your people are so adamant to the beauty of their own weather?

C.C. [My people, is there any beautiful girl here called Adanma? D.O wants a damsel.] -- NTA Icheoku "Bush"

8. D.O. I'll do my best, as much as possible to see that all those responsible for this act are compelled to indemnify for their losses.

C.C. [Offenders will bring a girl called Ify to the Idemili idol to console them.]

9. D.O. Tell him he is trying to pull wool over my eyes

C.C. [He say's there's a woman whose name is Nwula. She is also involved in this crime.] Nwula rises and raises a protest. -- NTA Icheoku "Push"

10. D.O. Attendance at the Entrepreneurship Development Programme is a sine qua non for benefiting from the loan scheme

11. D.O. She is suffering from oedema

C.C. [He says Odemena is killing you.] -- NTA Icheoku "Son"

In 6 the D.O simply says "Okay" (or "OK"), meaning "all right; satisfactory or in a satisfactory way" (Hornby, 2005); but the C.C decodes it wrongly to mean Oke which is a common Igbo abbreviation for the human name Okechukwu. Hence he (the C.C) starts calling out for the individual named Oke. In 7 he misconstrues the D.O's "adamant" for a lady Adanma, saying "D.O wants a damsel," consequent upon which a mother enthusiastically brings out her daughter named Adanma. So also in 8, "indemnify" is confused with the god Idemili and a lady Ify (that is, short for Ifeoma, Ifeyinwa, Ifeanyi, etc). The word "wool" in 9 is enough for the C.C to pronounce an innocent woman Nwula as being an accomplice in crime. In 10 "loan" becomes Lolo while in 11 the woman suffering from the disease "oedema" is told that she is being killed by an individual named Odemena. 


\subsubsection{Other Igbo Lexical Items}

In the other set of interlingual malapropisms, it is a common concept or object in Igbo, rather than a proper name, that is deciphered wrongly by the C.C in place of an English lexical item used by the D.O.

12. D.O. No, No, No, No! I'm simply talking about the rainy season and the dry season.

C.C. [He is saying Mother, Mother. Before you say anything in the court, you should know your mother] -- NTA Icheoku "Bush"

13. D.O. I believe he knew $\boldsymbol{a b}$ initio that his action was a dangerous one.

C.C. [You have pus in your head.]

There is murmuring. Okorie scratches his head all over.

OKORIE. [I have no pus.]

C.C. No milik for head.

D.O. What nonsense is he talking about?

C.C. Master, I think you say the man get pus for head- abu di nisi

14. D.O. She is a victim of male brutality. -- NTA Icheoku "Deadly"

C.C. [He saw a man who cut away the head of foofoo before swallowing it] -- NTA Icheoku "Hungry"

15. D.O. Make sure you treat them [women] gently because they are made fragile.

C.C. [(Somebody) poured sand in their mouths] -- NTA Icheoku "Hungry"

16. D.O. The Government has charged the N.D.E. to combat unemployment to redesign radical strategies to check unemployment in the country

C.C. [When the child grows up, he will be employed by the Government to give the youth pounded yam_until they are employed.] -- NTA Icheoku "Yehvoski"

Thus in 12 the D.O's denial of "No, No, No, No!" is perceived as "Nne-o, Nne-o, Ne-o, Ne-o!", meaning "Mother, Mother, Mother, Mother"; hence [He is saying Mother. Before you say anything in the court, you should know your mother]. And in 13 the latinism ab initio (which the D.O correctly explains later as meaning "from the beginning") is wrongly decoded as abu di n'isi ("pus for head") where abu is Igbo for "pus" and isi is "head". In 14 "brutality" is construed as "cut away the head of foofoo" because in some dialects of Igbo "to cut" or "kill" is buru or ogburu or bepu (Nnaji, 1985, p. 107) and bu is "to uproot" (Williamson, 1972, p. 73) while some dialects have foofoo (that is cassava meal or pounded yam) as utala. For 15 since "sand" is aja in Igbo (Nnaji, 1985, p. 281; Willliamson, 1972, p. 16), the C.C interprets the idea of a woman being "fragile" as implying that somebody "poured sand in their mouths." And in 16 -gies in "strategies" (as devised by the Nigerian government's National Directorate of Employment, N.D.E.) is wrongly considered as implying "yams" (ii in Igbo); hence "to redesign radical strategies to check unemployment" becomes "to give the youths pounded yam until they are employed."

Of the two sub-types of interligual malapropism, the misapplication of Igbo proper nouns is more pardonable because the D.O might be calling some appellations of the Igbo natives. But the latter type is most outrageous since there is no evidence that the D.O understands a single ordinary word is Igbo. Furthermore, the incompetence of the C.C is most eloquent as he unable to relate the words in the utterance to one another, when in fact the meaning of an utterance emerges not just from the word alone but from its relationship with other words.

The analyses in the above sections establish the veracity of Alexander Pope's paradox that "a little learning is," indeed, "a dangerous thing". The C.C and Zebi have "little learning" of the English language, and the "shallow draughts" they have taken of the language "intoxicate the brain." They have tasted the "Pierian Spring" but have certainly not drunk "deep" (Pope, 1973, lines $215-217)$. With their little learning they are not able to distinguish between minimal pairs; they are not able to know that phonological similarity does not mean semantic identity. While homonyms and polysems may result in ambiguity, one that has drunk deep from the Pierian Spring would be able to use contextual clues to disambiguate the utterances and save oneself from the topsy-turvydom that the C.C and Zebi have been subject to. The C.C can even be oblivious of the fact that the D.O would not be speaking any ordinary Igbo words as suggested above. Yet, because "shallow draughts intoxicate the [C.C's] brain" he does not consider it wise to readily admit his little learning. To him, he has to do some work or to be seen to be doing some interpretation. By implication, such malapropism is the lot of any bilinguals who would not take pains to "Drink deep" from the Pierian Spring of their L2. It is only "drinking largely" that "sobers us again" (Pope, 1973, line 218).

\section{Discussion: The Art in Malapropism}

In the above sections we have been looking at malapropism mainly as a linguistic and sociolinguistic issue. But Icheoku and Masquerade are works of art, in fact comedies, and undoubtedly the bulk of the humour derives 
from the malapropism displayed. Hence talking about Masquerade, Banjo (p. 1979, 11) rightly remarks that "a substantial part of the comedy in fact resides in the Chief's unmatchable use of English." This includes his malapropisms. Of course, the thrust of the comedy in Icheoku is the C.C's malapropist use and interpretation of English.

The crucial point is that the English featuring in both series is "a deliberate parody of a particular variety of English for artistic purposes ... in many cases is the only variety that its speakers are capable of" (Banjo, 1979, 11). This means that the comedy series mimic a sociolinguistic reality, for "the variety of English which is being parodied does exist outside the NTV studios" (Banjo 1979, p. 11). In order to attain maximum humour, this linguistic reality is deliberately exaggerated, the artist often creating (false) pun. What is happening is that the difficulties and challenges posed by the English language to Nigerian (and other ESL) users is being put on stage so that we can laugh at ourselves and recognise the role and problems of the English language in the life of the Nigerian (and other Anglophone multilingual) society from the colonial times up to the present. Firstly, the language was needed to enable the colonial masters to interact with the natives as mediated by the C.C. From then English has become a "world language that history has forced down our throats" (Achebe, 1975, p. 59) to enable the multilingual peoples to communicate within the often artificial boundaries that they have been forced into by the colonialists - such as in Masquerade where the characters reflect the linguistic spread of the country. But there is the veiled criticism of the fact that the English language constituted as much a problem as, if not more a problem than, colonialism itself, going by the potentials of miscarriage and travesty of justice that must have taken place with the instrumentality of interpreters like our C.C.

But what is it that is done by the writers and producers of, specifically, Icheoku to ensure that these episodes - with the threat to justice posed by the malapropisms - still end up as comedies - with happy denouement? We observe a combination of plot manipulation and linguistic cushioning through what we may call the feedback device. Usually a malapropism causes a stir in the audience because of the oddity of the content that is interpreted. This stir necessitates the D.O doubting the felicity of the interpretation and compels the C.C to relate back what he (the C.C) had related to the people. The misinterpretation is discovered and corrected. To cite only one example (from intralingual perceptive malapropism), in ["Fraudster"] we find this scene:

17. D.O. They are very good women. They are level-headed.

C.C. [You are good women but your heads will be cut off].

Wide-spread murmuring in the audience.

WOMEN. [screaming and pleading] We want things to be good. Why should he cut off our heads?

D.O. Count Clerk!

C.C. Sir

D.O. What's happening?

CC. Well, they say that they are doing good. I think you say that you go cut their head ... all their head be equal ...

D.O. No, No, No, No, No, That's not what I mean. I mean they did a good

something that's worth commendation, not condemnation; that's worth

commendation. Tell them that.

CC. [Forget what I said earlier. You are commended]. NTA Icheoku ["Fraudstar"]

While most impending crises springing from malapropisms are resolved in this way, there are a few cases that go unresolved. This is particularly so with interlingual malapropism. For example, in excerpt 9 above the audience would leave with the thought that Madam Nwula (ignorantly perceived in place of "wool") had been indicted of a crime. Indeed, she might be summoned to court to defend herself. Similarly in 10 above Madam Lolo (mistaken for "loan") keeps protesting until the end against the proposed use of her mortar as the C.C continually repeats that her mortar will be given to her only when the youths have returned from the train (the entrepreneurship training they will be engaged in to qualify for the loan). The following excerpts (cases of intralingual perceptive malapropism) give further credence to the dislocation of communication and justice arising from such malapropism:

18. D.O. Tell Amajuoyi that I advise him to go to the hospital where he'll be treated; he'll be given chloroquine or treated with any other quine family...

C.C. [You should go to the hospital where you see the queen's daughter called Caro-quine, who will cook dog meat for you. After the meal, you will be cured.] -- NTA Icheoku "Sisi"

19. D.O. The second skill you might call "Waste to Wealth," Under this scheme youths are taught how to use waste materials to create wealth.

C.C. [This one called "Waste to Wealth" is the plan to teach boys and girls how to make money with their waists.] - NTA Icheoku "Sisi"

20. D.O. The youths will be apprenticed to craftsmen and women in private and public institutions where they'll be taught the actual skills. 
C.C. [These youths will become apprentices and sent to some small buildings where some tricky men and women will teach them how to be tricky.]

$$
\text { -- NTA Icheoku "Yehvoski" }
$$

In 18 Amajuoyi will probably go to the hospital with the prospect of eating dog meat prepared by Caroquine ("chloroquine"), that is Caro ( short for "Caroline") who is the daughter of the queen ("quinine") in order to be cured of his fever. Again in 19 when the D.O says that youths would be "taught how to use waste materials to create wealth," the C.C confuses "waste" with its homonym "waist," saying that the plan would "teach boys and girls how to make money with their waists". This ludicrous misconception with the suggested immorality (sexual promiscuity) is left unresolved and the audience go home mumbling about this indecent proposal. So also in 20 the natives go away with the wrong impression that the "craftsmen and women" -- misconceived as crafty men and women -- will teach their youths how to be mischievous.

\section{Conclusion}

The above pages have discussed the concept of malapropism and the burlesque of this malaise in a second language context. Illustrations have been drawn from two Nigerian media comedies Icheoku and Masquerade. In all, it has been demonstrated that malapropism in a second-language bilingual context could be more complex than it would be in a monolingual (mother-tongue) context in that the confusion of words goes beyond poor mastery of the lexical items in the language being performed to include negative transfer of habits from the L1/MT to the L2 in phonology, lexis and semantics.

While the problems involved in such second-language malapropism may have been exaggerated for the purpose of artistically ridiculing the real-life defect, there would be little doubt that the observations would be useful in shedding more light on this global linguistic problem and extend the frontiers of the attempts to understand the challenges in second language acquisition and learning.

\section{References}

Achebe, C. (1975). Morning Yet on Creation Day: Essays. London: Heinemann.

American Heritage Dictionary of the English Language (2009).

American Heritage New Dictionary of Cultural Literacy online http://www.answers.com/topic/malapropism. Retrieved 30 September, 2014.

Banjo, A. (1979). "Beyond Intelligibility: A Presidential Address." Varieties and Functions of English in Nigeria. Ed. Ebo Ubahakwe. Ibadan: African University Press. 7-13.

Encarta Online Dictionary (2014). “Malapropism.” http://www.answers.com/topic/malapropism. Retrieved 30 September, 2014.

Encyclopaedia Britannica online "Malapropism." http://www.britannica.com/eb/article.9050280/malapropism. Retrieved 30 September, 2014.

Hoffmann, C. (1991). An Introduction to Bilingualism. London: Longman.

Hornby, A.S. (2005). Oxford Advanced Learner's Dictionary of Current English. $7^{\text {th }}$ ed. Oxford: Oxford University Press.

Iroha, J. and the Masquerades (n.d). "The Visit of Mr. Bankrovitch.” L P and Audiocassette. Lagos: PolyGram Records.

Jowitt, D. (1991). Nigerian English Usage: An Introduction. Ikeja, Lagos: Longman Nigeria.

Kachru, B. B. (1983). "Model for Non-native Englishes.” Ed. Braj B. Kachru The Other Tongue: English across Cultures. Oxford: Pergamon Press. pp. 31-57.

Marriam-Webster's Online Dictionary (2007). http://www.merriam-webster.com/cgibin/dictionary?book=Dictionary\&va $=$ malapropism $\& x=0 \& y=0$. Retrieved 30 September, 2014.

Nigerian Television Authority (NTA) (1988). "Bride of War". Icheoku. Videotape. Lagos: NTA.

- - - (n.d.). ["Bush Burning."] Icheoku. Videotape. Enugu: NTA.

- - - (1989).“Deadly Hunter.” Icheoku. Videotape. Lagos: NTA.

- - - (1992). [“The Fraudster”]. Icheoku. Videotape. Enugu: NTA.

- - - (1989). "Hungry and Thirsty." Icheoku. Videotape. Lagos: NTA.

- - - (n.d.). ["Inheritance"]. Icheoku. Videotape. Enugu: NTA.

- - - (1989). "One Man's Meat." Icheoku. Videotape. Lagos: NTA.

- - - (1988). "Push Me: I Push You.” Icheoku. Videotape. Lagos: NTA.

- - - (1989). "Sisi Agee". Icheoku. Videotape. Lagos: NTA.

- - - (1988). "The Son Digger.” Icheoku. Videotape. Lagos: NTA.

- - - (1989). "Yehvoski." Icheoku. Videotape. Lagos: NTA.

Nnaji, H.I. (1995). Modern English-Igbo Dictionary. Onitsha: Gonaj Books.

The Oxford English Dictionary (1989). $2^{\text {nd }}$ ed.

Okpala, C. (1993). "Permission Me to Make This Spokage" Unpublished Interview with Diri I. Teilanyo, Enugu, 
February 1.

Pope, A. (1973). "Essay on Criticism." The Oxford Anthology of English Literature. Ed. Frank Kermode and John Hollander. Oxford: Oxford University Press.

Schmied, J. (1991). English in Africa. London: Longman.

Sheridan, R.B. (1966). The Rivals. New York: Dell Publishers.

Teilanyo, D. I. (2003). "The Use of Non-Standard English for Artistic Expression: The Examples of Icheoku and Masquerade." Unpublished Ph.D Thesis, U of Benin, Benin City, Nigeria.

-- -- -- (2003). "The Use of Bombast in Nigeria: The Examples of Icheoku and Masquerade." Africa Today, $50(1), 77-104$.

-- -- -- (2009). "Literary Usage in English as a Second Language in Nigeria: A Study of Icheoku and Masquerade." Africa Today, 54(4), 73-121.

-- -- (2010). "Paralinguistic and Non-Verbal Props in Second Language Use: A Study of Icheoku and Masquerade in Nigeria." Language in India. 10(11), 52-65.

$\mathrm{http}: / /$ languageinindia.com/nov2010/teilanyoparalinguisticnigeria.html

-- -- -- (2011). "Malapropism in a Second-language Context: A Study of Icheoku and Masquerade." Calabar Journal of Liberal Studies (CAJOLIS). 15(1), 40- 63.

Wikipedia Online Dictionary (2006). http://en..wikipedia.org/wiki/Malapropism. Retrieved 30 September, 2014.

Williamson, K. (1972). Igbo-English Dictionary (Based on the Onitsha Dialect). Benin City: Ethiope Publishing Corporation.

Zebrudaya and His Concert Party (n.d). "Clarus the Psychantric.” LP and Audiocassette. Aba: Ben Nigeria.

\section{Notes}

${ }^{1}$ These abbreviations feature in the works themselves: "C.C" is used in the list of cast and dramatis personae in Icheoku; "Zebi" is the pet form used by Chief Zebrudaya's wife Ovuleria.

${ }^{2}$ Braj B. Kachru (1983, p. $41-42$ ) has identified and discussed four functional aspects of non-native "Englishes" -- the instrumental, the regulative, the interpersonal and the imaginative/innovative. Kachru explains: "In each function we have a cline in performance which varies from what may be termed an "educated" or standard variety to a pidginized or "broken" variety. The varieties within a variety also seem to perform their functions, as they do in any native variety of English' (p. 41).

${ }^{3}$ NTV is the acronym for National Television, the name Nigeria's Federal Government-owned television body was called before it was renamed Nigerian Television Authority (NTA).

${ }^{4}$ These patterns, with numerous instances from these texts, are discussed elsewhere (Teilanyo 2003a, p. 107 $-117)$.

${ }^{5}$ The utterances are fraught with ungrammaticalities. This paper concentrates on perceptive interlingual malapropism alone. Other areas of linguistic deviance are treated elsewhere (Teilanyo, 2003a, 2003b, 2010). The misinterpretation of English idioms and figurative expressions is also treated in detail elsewhere (Teilanyo, 2009) since these involve a deeper and more contextualized level of meaning than the literal usage we are concerned with here.

${ }^{6}$ Code-mixing is often distinguished from code-switching: while the latter is usually intersentential and situational, the former is intrasentential (mixing lexical items from more than one language) (See Schmied, p.182-183, 186; Hoffmann, p. 95-96) 